taking a decision as uncongenial to him as it is to her. To quote from Michael Foot's Aneurin Bevan, 1945-1960," "He agreed that specialists would encourage the establishpaying patients in hospitals. The risk was obvious, but the representatives of the Royal Colleges of Physicians and Surgeons had told him that without this concession some specialist would encourage the establishment of private nursing homes. To get the specialists into the hospitals and to keep them there as regularly as possible was crucial to the whole enterprise. He bowed to the necessity before he had ever opened consultations with the B.M.A."

The minority of patients who would like to pay for privacy and a specialist of their choice in their hospitals, which as taxpayers they provide and maintain, have, I submit, the right to demand that this should not be denied them. When Mrs. Castle had a bed in the private wing of University College Hospital she, as a Minister of the Crown, simply had to have a room of her own with a telephone so that she could continue to conduct essential business. To call this queue-jumping is to ignore the fact that the time and services of some people are far more important to the community than the time and services of most of us.

No one would want the Prime Minister and his ministerial colleagues, and their counterparts in the opposition, to add their names to a long waiting list or to be obliged to go into nursing homes likely to be less well equipped than a modern N.H.S. hospital. When it comes to general practitioner treatment I expect our governors have to have private practitioners. When $\mathrm{Mr}$. Harold Wilson had his recent indisposition after a visit to Paris no one would have expected him to sit in the waiting-room of a health centre or to be told that his doctor could not visit him for two or three days. And if he needed hospital treatment he would, for security reasons alone, have had to have a private room, preferably in a well-equipped modern hospital.

And then there are many other persons whose time and services are more valuable to the community than those of the ordinary man in the street. They need privacy to conduct their business as leaders of industry and managers of public enterprises. Though as a medical man I might expect extra consideration from my old teaching hospital if ill, I preferred to subscribe for years to a medical provident scheme. This enabled me to pay the surgeon of my choice for severe operations on my wife in the private wing of his hospital. I think it is unwisepolitically unwise-of Mrs. Castle to deny this to others who take this prudent precaution-deny to them the facilities she took advantage of when in need of expert care herself. To quote from your excellent leading article (4 January, p. 4), "Is she really so indifferent to the welfare of British medicine?"

May I end, Sir, by suggesting that it is time we stopped describing a medical service as a health service. And let us at the same time restore to some of its old dignity what was a fine health service, called the Public Health Service.-I am, etc.,

Hugh CIEGg

London N.W.3

1 Foot, M., Aneurin Bevan, 1945-60. London,

\section{G.P.s and the Crisis}

SIR,-Surely now, if ever, the moment of truth for the medical profession is arrived, and I for one wish to express my support for our consultant colleagues in the action they are taking. I much regret that such action has been left to a small and perhaps vulnerable section of the profession and, while firmly supporting the B.M.A. in this matter, feel that a united front might have been more appropriate. It is scarcely possible to doubt that the turn of general practitioners will come.

The medical profession, by and large a dedicated body of men and women with a sense of vocation, have in the majority slaved over the past 26 years to make the Health Service a success. Their reward for this effort has been repeated obstructive interference with their professional rights and a salary scale that has made them the objects of pity and incredulity by other medical professions in the free world.

As much as anything we are fighting for self-determination and the freedom to treat our patients in the way we think fit, either within the Health Service or without it. We must brook no more interference, no more meddling, no more political intrigue, and must demand that a totally non-political corporation should be set up, similar to the B.B.C., to run the service.-I am, etc.,

\section{F. V. GRIFFIthS}

London S.W.10

SIR,-The hospital consultants are showing action; so must we general practitioners. There is only one way: resign. This does not mean go on strike. Of course we shall still attend to all patients, but a fee will be charged. Prescriptions will not be written on EC10s; therefore the patient will have to pay for the prescription at the chemist. It will take only a week or two for the public to inform the Government of their displeasure. We shall then receive our just increase in income to maintain our standard of living. We must not wait until April; it will then be too late.

The B.M.A. must send to all general practitioners a referendum asking if we are willing to resign, with no other alternative. I am sure that the positive response will be great.-I am, etc.,

Upminster, Essex

BARRIE HANSTEAD

\section{Well-woman Clinics}

SIR,-It is distressing that the cost effectiveness and priorities of patient care need to be evaluated as a medical compromise in our underfunded Health Service. But if this is to be we must support the challenge of Mr. R. T. Burkitt (7 December, p. 588) in questioning the value of well-woman clinics for young patients. However, not wishing to appear to be the Luddites of preventive medicine, we would urge the creation of menopause clinics within the N.H.S. as an alternative. Apart from the growing evidence that the climacteric is an insidious deficiency state requiring oestrogen therapy in order to protect the skeleton and general well-being, this selection of the female population offers a greater source of early and treatable disease.

The first 200 patients attending the two menopause clinics in our hospitals have yielded four positive cervical smears (two carcinoma in situ), three breast lumps (one early carcinoma), and one each of endometrial carcinoma, melanoma, diabetes mellitus, hypertension, and hypercalcaemia.

The postmenopausal population is clearly a high-risk group. It is also our belief that women can more readily be lured into wellwoman clinics by their distressing vasomotor symptoms, their diminished sexual responsiveness, and their hopes, however misplaced, of "feminine forever" than by a primary concern about the presence of early disease.-We are, etc.,

JOHN STUDD DAVID ORAM SUDIP CHAKRAVARTI

Department of Obstetrics and Gynaecology, King's College Hospital,
London S.E.5

BEN MOORE

Birmingham and Midland Hospital for Women,

Birmingham

\section{Haemophilus influenzae in the Elderly}

SIR,-A leading article (1 June, p. 462) recently pointed to the increase in the prevalence of infections with Haemophilus influenzae in the past three or four decades. Dr. Susannah J. Eykyn and others in the same issue (p. 463) described an apparently new trend towards meningitic infection with this organism in adults, but in your articles and in the available literature it is emphasized that the main importance of $H$. influenzae is in infections of infancy and childhood. In my experience, however, the organism is already a significant cause of morbidity, and occasionally mortality, in the elderly population.

In a consecutive series of 42 patients admitted to a geriatric assessment unit nasal swabs, throat swabs, and specimens of sputum were cultured. $H$. influenzae was identified from the sputum as the causative organism from four patients, all male, who had clinical evidence of chest infection and from the sputum of two women who were asymptomatic. Two of the men and one of the women had $H$. influenzae in their sputum on admission to hospital; both the men died of bronchopneumonia, in spite of treatment with apparently appropriate antibiotics, within a month of admission. The rest of the positive sputum cultures presumably resulted from cross-infection in the hospital wards within one week of admission of the patients, who were initially free from chest infection.

In all six patients $H$. influenzae was shown in the laboratory to be sensitive to ampicillin, tetracycline, and co-trimoxazole. Resistance to cephaloridine was noted in several specimens from one of the patients who died. Though resistance to other drugs was not encountered in laboratory tests, $H$. influenzae proved to be much more difficult to eradicate clinically than its theoretical sensitivity suggested. The prognosis was clearly worst for those patients infected with the organism before admission, but the introduction of $H$. influenzae into a geriatric unit provided a significant and continuing morbidity among 